\title{
Awareness of data privacy on social networks by students at Qassim University
}

\author{
Abdullah Alabdulatif* and Fahad Alturise \\ Assistant Professor, Computer Department, College of Sciences and Arts, Qassim University, Al-Rass, Saudi Arabia \\ Received: 29-June-2020; Revised: 05-September-2020; Accepted: 08-September-2020 \\ (C)2020 Abdullah Alabdulatif and Fahad Alturise. This is an open access article distributed under the Creative Commons \\ Attribution (CC BY) License, which permits unrestricted use, distribution, and reproduction in any medium, provided the original \\ work is properly cited.
}

\begin{abstract}
In the socialization paradigm, digitalization is the primary function. Social Networking Sites (SNS) are a means of achieving advanced communication. For the last few decades, SNS have become the most widely used media of socialization and connectivity between people. SNS utilize personal information sharing, which raises privacy concerns in users due to the sensitive, confidential data which is necessarily gathered. This paper investigates awareness regarding the information privacy of students of Qassim University who use SNS. The research comprises a survey exploration to study how the students of Qassim University interact with SNS in terms of privacy. The literature review explores the theoretical privacy concerns with respect to SNS, including measuring awareness of privacy settings for their accounts in SNS. Also covered is student reaction to privacy violations. Data were collected using a questionnaire which sampled 913 respondents, who were selected from various levels and departments using random sampling methods. The analysis revealed that the majority of the users in every SNS are concerned about their privacy and personal information, and $69.4 \%$ contacted the government about privacy violations. This paper aims to investigate awareness regarding information privacy in the students of Qassim University using SNS.
\end{abstract}

\section{Keywords}

Social networking sites, Qassim university, Privacy, Privacy settings, Privacy violations.

\section{Introduction}

Around the world, people are interconnected with each other through SNS. Billions of the world's populations benefit from instant communication using simple and quick social media applications through safe and reliable profiles [1]. SNS allow users to form a profile of their choice, i.e. fully or semi-accessible by other users within a restricted framework [2]. Social media and SNS, like Facebook, have records of confidential and personal information, including birthdates, e-mails, phone numbers, political outlooks, physical addresses, and photographs. Moreover, pictures can be of significant events, ceremonies, or occasions.

The overall biography inside a user's profile holds detailed, private information on social media, which could adversely affect individuals if it was compromised.

*Author for correspondence 194
Some of the negative social media uses include limiting employment opportunities $[3,4]$ identity theft, and fraudulent actions [5].

Regarding online confidentiality, three different types of information privacy are distinguished [6], namely (i) informational privacy (ii) social privacy and (iii) personal privacy. Based on recent studies, the second type, social privacy, is mainly focused on social media profile privacy settings, which play a vital role in facilitating the mechanism of social media connectivity.

During early 2020, online social networks grew very quickly, which directly impacted their usage within Saudi Arabia. Out of the 33 million population of Saudi Arabia, by June 2020, more than 18 million are active Twitter users, and 20 million are active Facebook and Instagram users [7]. It can be clearly seen on social media that all active users, not only from Saudi Arabia but from the rest of the world, are also regularly posting and sharing detailed personal, confidential information that gives rise to serious online privacy issues [8]. 
The lack of empirical research which is theory-driven regarding the importance of social media privacy in the Middle East makes this present study valuable to both academic and industrial communities for awareness purposes [9]. Detailed studies aim to identify and assess various security awareness about social networks [8].

In this study, the main aim is to investigate awareness regarding information privacy using SNS in the students of Qassim University. The primary objectives include (i) Identify the privacy functions of SNS and the related concerns about them (ii) explore motivations to reveal the data on SNS and be aware of personal privacy data (3) determine the awareness of information privacy during the use of SNS by the students of Qassim University.

\section{Literature review}

In this fast-growing world, SNS engage users to communicate, in the virtual community, with other network users. SNS users connect with other users through sharing and posting personal information. Despite the personal information involved, new videos and images are shared in an instant. This sharing can be performed in-profile as well as in realtime conversations using chat functionalities [10]. In this scenario, each user has the ability to create online friends in the matching network and to share common interests or collaborations. Note that all SNS are associated with a major goal to make its nomenclature different than other sites, and they vary depending on the site [11]. The SNS networks give access and the freedom to users to openly communicate with new contacts in the network, but also to reach out to people from their offline group of friends.

Interaction among users has been significantly impacted by the advanced, ongoing development of information and communication technologies. This phenomenon is dominant, particularly in the case of people who use mobile devices for communication purposes. Since it is not clear to mobile web users where their personal information is stored, and who can use it, it is important to protect mobile web user data and brief users on data privacy. Confidentiality in these paradigms has become a real challenge.

In early 2019, SNS networks grew in Saudi Arabia, where, out of 33 million people, around 18 million are Twitter users, 20 million are Facebook users, and the remaining five million use Instagram, Snap chat, etc. [7]. It can be clearly seen, in social media, that all active users, not only from Saudi Arabia but also from the rest of the world, continually post and share detailed personal, confidential information. This sharing gives rise to serious online privacy issues in three different categories, namely privacy, social privacy, and personal privacy. Details mainly focusing on social media privacy settings [12], and the surrounding concerns, are discussed in the following sections. Literature regarding privacy shows that sharing the personal data of customers relies upon data sensitivity, whereas the willingness to share it is associated with individual inherent risk.

\subsection{Privacy}

Different authors and researchers define confidentiality differently. The author [13] defined privacy as the protection of personal information from misuse by others, and the allowance of only certain authorized entities to access personal information. The author [14] described privacy as a set of policies that force systems to protect private information. Privacy also applies to user location and other details relating to the user [15]. Based on various studies with wide-ranging aspects, the concept of privacy is found to be diverse, having no single definition which incorporates all aspects.

\subsection{Privacy concerns}

In this digital age, personal information has been found to be the most critical form of retained data. There are also moral issues around privacy, like psychological, philosophical, lawful subjects, and sociological subjects. From a broad-ranging view, privacy purpose is also contemplated in the view of various perspectives [16]. In SNS, privacy is considered a subset of data privacy. For active social media users, privacy is psychological based on protecting their personal, confidential data against offline scams. Various researches show a range of perspectives in the information technology (IT) domain based on two functions. The first is explained as privacy is explained as the "claim of individuals, groups, or institutions to define for themselves when, where, how, and to what degree of personal information about the user is shared with third parties [17]. The second is explained as "the product-based aspect regarding the monetary use of an individual's data for exchange and commercialization. In this process, third parties are always ready to analyse, gather, and vend individual user information [18].

Privacy management is most widely considered to be the control of self-revelation of individual as well as private data. In the self-revelation process, an 
individual is willing to share their personal data with other people [19]. The level to which the data is exposed by each user to others is identified through privacy management. In this process, the two basic elements of sharing data are (i) willingness to share data and (ii) user awareness [20]. Data classification characterizes the degree to which users are willing to share their information, whereas the sensitivity of data is considered to be the usage of personal information for commercial purposes [21]. Literature regarding privacy shows that sharing a customer's personal data relies upon data sensitivity, whereas the willingness to share it is associated with inherent individual risk [17].

\subsection{Motivation to reveal data on SNS}

In SNS the size of the website is a critical element that specifies contact lists as well as users. It is user eagerness that motivates users to share their information with their online list of contacts. Each user procures the network to reinforce their feelings based on the reactions of an enlarged SNS network size [17]. The data holder uses certain settings to constrain the sharing of personal details [22].

\subsection{Awareness of personal privacy data}

While registering on a SNS, personal information is required as input, which creates worry in almost every user. Different studies have indicated the strong concerns of users regarding privacy [23] [8]. In the base of communication experience, awareness is defined as new concept acknowledgment and its transformation [24]. Some people are looking for news and exposure in a communication network chain for trending to present their thoughts on different aspects [25]. For social recognition, while visiting social networks, individual awareness can move users toward various applications and exercises. The person forms a bridge between their past and future plans in comparative circumstances [26].

SNS are considered to be responsible for managing user's data security, and whenever the user feels unsafe regarding their respective data, after knowing it has been manhandled, the user becomes dissatisfied with its commitments. Detailed extensive examinations and findings reveal that individuals have experienced privacy invasion [17]. For this purpose, almost all SNS have high levels of flexibility in their privacy settings; however, it is never an exact science. Privacy flexibility is offered to protect one's profile from friends, the public, and semi-friends or acquaintances. In some cases, settings provide further options within each topic, which offer checkboxes for various options to expose or disclose data to certain people or groups of people.

\subsection{Privacy and financial incentives}

Incentive measurements are regularly implemented by SNS to provide individual user data. In the case of shopping coupons and transactions, clients are drawn in and encouraged to reveal information [27]. The enforcement element is a minor advantage that can be viewed where SNS collect all private data to facilitate users' privacy. According to growing user enthusiasm, financial incentives improve userperceived behaviour in sharing personal information [28]. In this regard, SNS developers maintain a constant code of conduct based on proclamations issued regarding data collection, data storage, and essential user routes to understand the policy and develop trust [29]. Only SNS networks with transparent security approaches are trusted, as opposed to those which don't focus on security. Users are eager to provide data to sites with adequate defensive measures. User concerns and confidence regarding privacy and information can be improved by explicit privacy management and privacy policies in which the user is urged to share data [30].

User personal information can be exploited to the extent as prescribed in privacy policies based on legal notices. This information includes name, marital status, address, date of birth, financial records, contact information, credit card information, and medical history, etc. Generally, all privacy policies thoroughly explain comprehensive related information regarding how much and how user information will be used. Furthermore, they provide disclosure around how the data are collected, stored, and tracked. It explains the rule which users need to know about the data uses by the website. In recent years, people often use SNS as anonymous and unethical users to ensure data security and confidentiality. Therefore, the privacy policy is vital to such websites [31].

\section{Methodology}

This study aims to investigate awareness regarding information privacy by students of Qassim University who use SNS based on research questions responded to in a survey. Previous studies show that questionnaire-based survey studies on information privacy are indicated to be the most useful method of data collection. Some studies include free format questions [32], and selective interviews [33], to get additional data. A few questionnaires have been on 
paper, but most were web-based [1] [34] [17]. For this study, web-based was chosen because most, if not all, study respondents can manage an online questionnaire.

The questionnaire was developed based on closedended questions utilizing some available questionnaires, which underpinned the development. The resulting questionnaire has been reviewed by professional colleagues in the computer field for confirmation and effectiveness. Furthermore, a statistical consultant and English and Arabic language experts were also involved to ensure clarity, proper language structure, and the elimination of language ambiguities. Overall, the pilot test was performed on seven participants, which resulted in minor modifications.

In this survey, two different sets of questionnaires were set where Table 1 responded to demographic information, and Table 2 attended to various matters of information regarding privacy. The primary goal was to question respondents' perspectives about privacy and confidentiality matters on Social Networks such as privacy setting, privacy controls, and included general, personal viewpoints about privacy awareness. The overall questionnaire questions were selected based on four different groups, namely (i) Questions 1-4 in Table 2 gather general information related to social networks and daily time spend (ii) Questions 5-7 investigate user attitudes and the way information is used for disclosure and data privacy control (iii) Questions 810 determine user awareness and understanding of the privacy policies and terms of use of Social Networks.

The survey participants had access to ten discreet questions and four demographic queries. All participants were guided to select one or more answer(s) based on the type of query within a set frame of answers.

\subsection{Results of data collection}

Data were collected by sharing a link with students of Qassim university in various colleges in the Kingdom of Saudi Arabia. All the participants were provided with information sheets and Arabic language questionnaires. This survey link was active for seven days. In this survey, a total of 933 respondents participated from whom responses were gathered and later used for analysis.

\subsection{Demographic characteristics}

Out of the 913 respondents, 398 (43.6\%) were from arts and humanities colleges, and $453(49.6 \%)$ were from science colleges, with just 62 (6.9\%) from medical science colleges. For gender, 289 (31.7\%) were male, and 624 (68.3\%) were female. Most study undergraduate degrees 794 (87\%), and 64 (7.1\%) are in the foundation program at university, with $55(6 \%)$ in postgraduate degrees. Age-wise, $779(85.3 \%)$ were between 18 and 24 years old, and $107(11.7 \%)$ were between 25 and 29 years old. Just 27 (3\%) were over 30 years old. Table 1 presents the summary of demographic profile of the respondents, while Table 2 shows the survey questions response.

Table 1 Demographic profile of respondents

\begin{tabular}{|c|c|c|c|}
\hline \multirow[t]{2}{*}{ Variables } & \multirow[t]{2}{*}{ Answers } & \multicolumn{2}{|l|}{ Responses } \\
\hline & & Frequency & Percent \\
\hline \multirow{3}{*}{$\sum_{4}^{80}$} & $18-24$ & 779 & $85.3 \%$ \\
\hline & $25-29$ & 107 & $11.7 \%$ \\
\hline & More than 30 & 27 & $3 \%$ \\
\hline \multirow{2}{*}{ 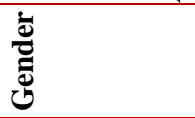 } & Male & 289 & $31.7 \%$ \\
\hline & Female & 624 & $68.3 \%$ \\
\hline \multirow{3}{*}{ 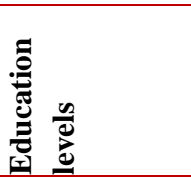 } & Foundation & 64 & $7.1 \%$ \\
\hline & Undergraduate & 794 & $87 \%$ \\
\hline & Postgraduate & 55 & $6 \%$ \\
\hline \multirow{3}{*}{ 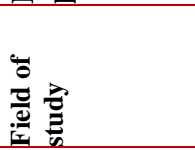 } & Arts and Humanities & 398 & $43.6 \%$ \\
\hline & Sciences & 453 & $49.6 \%$ \\
\hline & Medical sciences & 62 & $6.9 \%$ \\
\hline
\end{tabular}


Abdullah Alabdulatif and Fahad Alturise.

Table 2 Questions and answers in the survey

\begin{tabular}{l}
\hline Survey questions \\
\hline 1. What social network(s) do respondents use? \\
\hline 2. How long have respondents used social media? \\
3. How did most respondents access Social media? \\
4. On average, how many hours per day is spent \\
on social network(s)?
\end{tabular}

5. Why do respondents use social media?

Answer options

Facebook, Twitter, Instagram, Snapchat, WhatsApp, other

$<1$ year, 1 - 2 years, $3-4$ years, $>4$ years

Smartphone, laptop, tablet, desktop

$<1$ hour, 1 - 2 hours, $3-4$ hours, $>4$ hours

Mix with friends, meet new people with similar hobbies, express my opinion or share my knowledge, I use different social media platforms for different purposes, not sure.

6. How often does the respondent post, share, or comment publicly on own and/or other SN pages?

7. Which of the following privacy control mechanisms is the respondent currently using?

Never, occasionally, sometimes, often, frequently.

Control how others can find me, block spam, control who can message, restrict visibility of my profile, restrict photo tagging, set alarm if unknown login occurs, I don't use any mechanism.

8. When joining a social network, which answer best describes the respondent?

Never read the terms of service but agreed to join, only sometimes read the terms yet still agree to join, always read the terms still agree to join, always read the terms and do not join if disagree

9. Regarding social network privacy policies, which answer best describes the respondent?

Not aware; don't read and can't find them, aware but never read them, aware; sometimes read them but have no concern with privacy, aware; read, and take info. privacy seriously and act adequately.

10. If others try to uncover the respondent's private information from the user's social network Very difficult, somewhat difficult, not too difficult, not at all difficult. pages, how difficult would be?

\subsection{Information about social networks}

The results showed that WhatsApp was the dominant SNS used with a response rate of $89 \%$ (813). Facebook, which is now an old SNS, had the lowest percentage of users at $3.9 \%$ (36). Snapchat is the newest social network between the other four networks, with a response rate of $74.8 \%$ (683). $77 \%$ (703) of respondents use Twitter. 62\% (566) of students use Instagram. Finally, about $6.5 \%$ (59) of participants use other social media. Table 3 represents the findings and the rankings of the SNSs by the survey participants.

The analysis displayed in Figure 1 shows that $86.9 \%$ of the respondents have used social media from more than four years, $10 \%$ have used it for between three and four years, $1.6 \%$ have used it from one to two years, whereas $1.3 \%$ has used it for less than a year. All the students use social media through different devices.
Table 4 illustrates that $99 \%$ of the users use smartphones, $28.9 \%$ are using laptops, $12.4 \%$ use tablets, and only $5.1 \%$ are using a desktop for social media.

Figure 2 shows daily usages are $43.5 \%$ of the students spend more than four hours on social media, $36.5 \%$ use it for three to four hours, $14.5 \%$ spend over one to two hours on it, and $5.5 \%$ spend less than an hour on social media.

In addition, Table 5 confirms that $77.5 \%$ of the students spend time on social media to connect with friends, $28.3 \%$ try to connect with new people, $54.9 \%$ use it for multiple purposes, whereas $35.9 \%$ use it for sharing and expressing their personal views with other people.

Furthermore, Figure 3 illustrates that more than 300 people sometimes share their opinion with the public, while about 300 rarely share on social media.

Table 3 Chosen social media by respondents

\begin{tabular}{lll}
\hline Social media & Frequency & Percent \\
\hline Facebook & 36 & $3.9 \%$ \\
\hline Twitter & 703 & $77 \%$ \\
\hline Instagram & 566 & $62 \%$ \\
\hline Snapchat & 683 & $74.8 \%$ \\
\hline WhatsApp & 813 & $89 \%$ \\
\hline Other & 59 & $6.5 \%$ \\
\hline
\end{tabular}




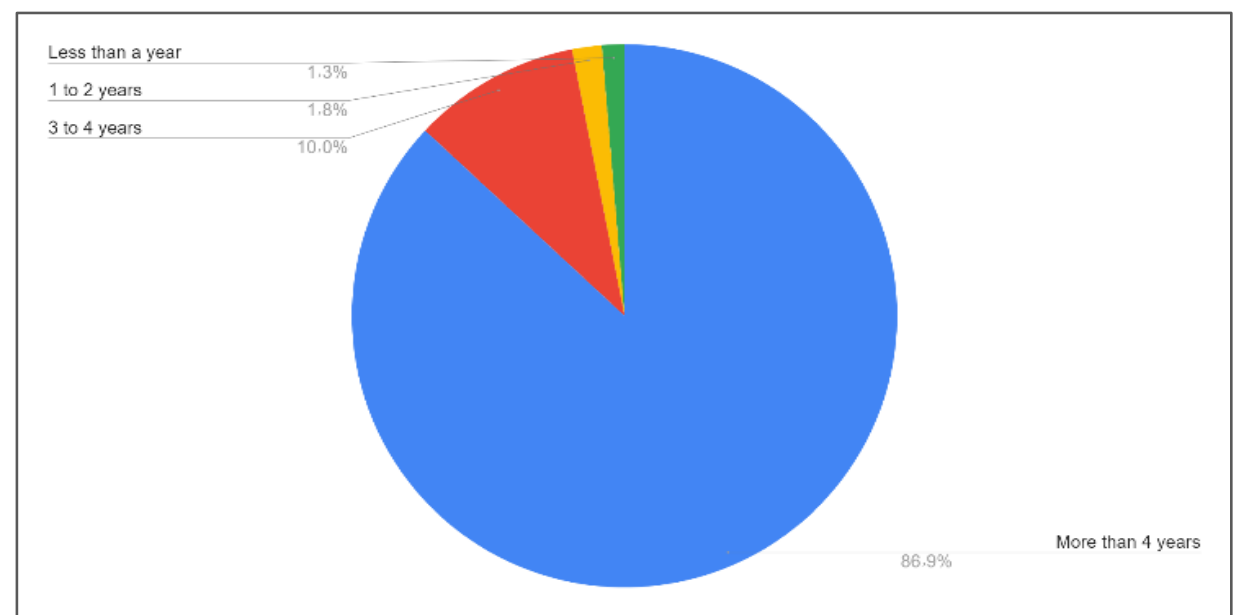

Figure 1 For how long have you been using social media?

Table 4 By what means do you access social media?

\begin{tabular}{lcc}
\hline Device type & Frequency & Percent \\
\hline Smartphone & 904 & $99 \%$ \\
\hline Laptop & 264 & $28.9 \%$ \\
\hline Tablet & 113 & $12.4 \%$ \\
\hline Desktop & 47 & $5.1 \%$ \\
\hline
\end{tabular}

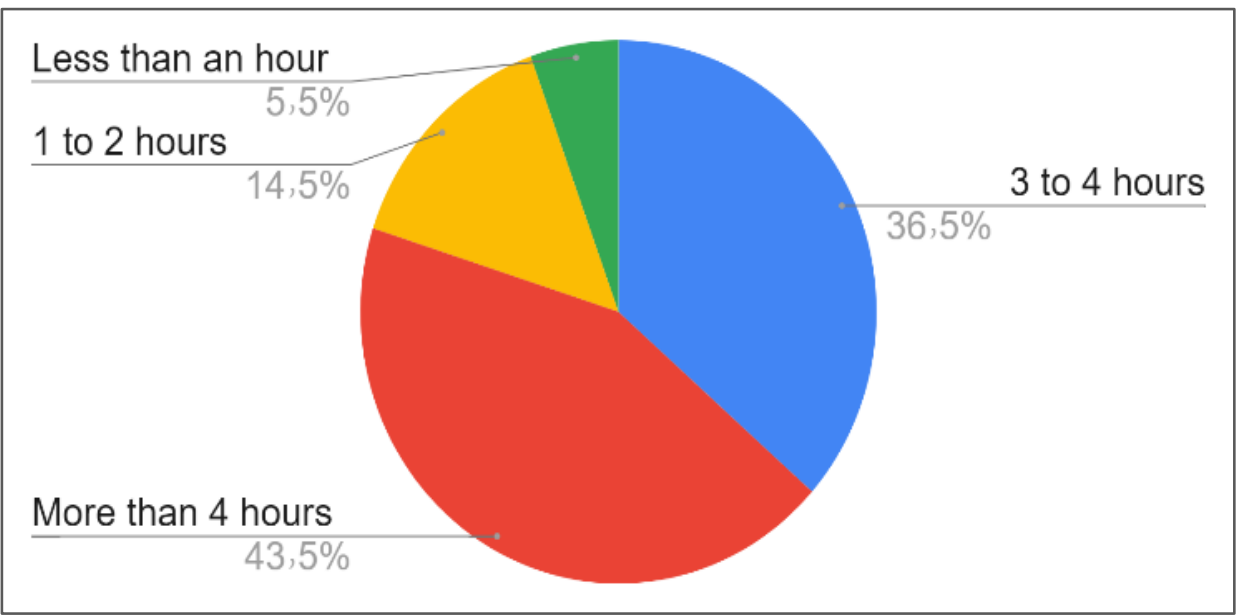

Figure 2 How many hours of social media per day?

Table 5 The goals of using social media

\begin{tabular}{lll}
\hline Social media & Frequency & Percent \\
\hline To connect with friends & 708 & $77.5 \%$ \\
\hline To connect with new people who have similar interests & 258 & $28.3 \%$ \\
\hline I use different social media platforms for different purposes & 501 & $54.9 \%$ \\
\hline To express my opinion or share my knowledge on a topic & 328 & $35.9 \%$ \\
\hline Not sure & 71 & $7.8 \%$ \\
\hline
\end{tabular}


Abdullah Alabdulatif and Fahad Alturise.

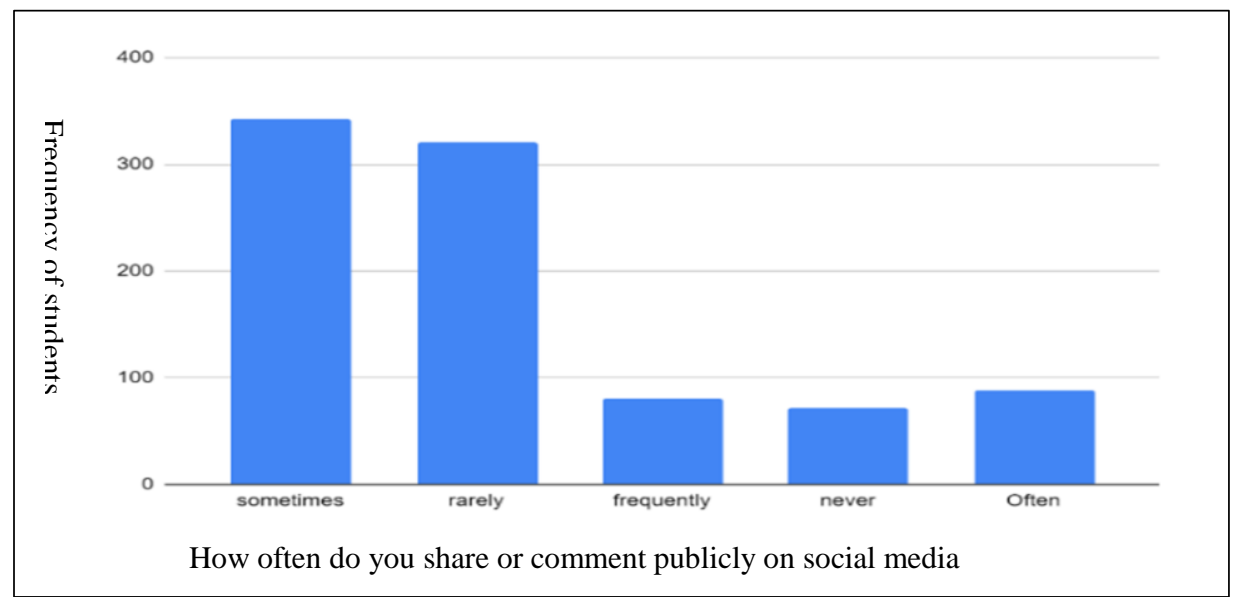

Figure 3 How often do you share or comment publicly on social media?

Regarding privacy, Figure 4 illustrates that $88.1 \%$ are concerned about their privacy, and sharing depends on what they themselves set, whereas $1.5 \%$ use the default settings, $3.3 \%$ ask a technical person to help, and $7.1 \%$ rely on friends and family members.

Details of the control over personal information, sharing of photos, tagging and spam messages are shown in Table 6, where $44.1 \%$ have control over searching, and $34.1 \%$ of users avoid spam messages, $36.5 \%$ control inbox messaging, $39.9 \%$ restrict profile viewing, $15.2 \%$ block tagging, and $33.4 \%$ set an alarm when a login is detected from any other source.

Figure 5 shows when any new user logs in whether they study the terms and conditions or ignore them. It can be clearly seen that more than 300 students agree that when they $\log$ in as new user, they ignore the terms and conditions and don't even read them. Only less than 100 people study the full details while logging in to social networks.

From Figure 6, it can be clearly seen that the majority of the users don't read terms and conditions while joining social networks. Analysis (as shown in Figure 6) reveals that about $34.4 \%$ are aware of privacy concerns but still ignore the terms, whereas $32.7 \%$ of the students take all the terms and conditions regarding privacy seriously, and read them all, while only $12.6 \%$ ignore the terms and conditions about privacy.

However, Figure 7 shows that if anyone tries to disclose user information, about $33.8 \%$ of them believe it has a high impact, whereas $36.8 \%$ show it is somewhat difficult, and $22.5 \%$ ignore it. All the significant users avoid even ads coming up in front of them.

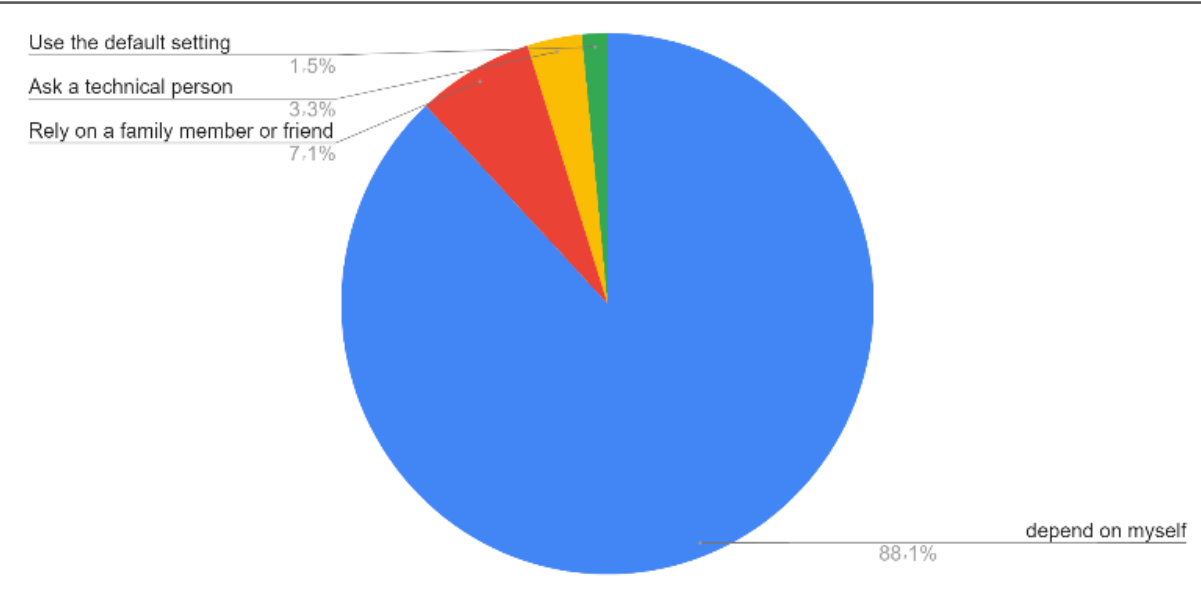

Figure 4 Do you adjust the privacy settings for your account(s) on social media? 
Table 6 Which privacy controls do you use?

\begin{tabular}{lcc}
\hline Social media & Frequency & Percent \\
\hline Control how others can find me. & 403 & $44.1 \%$ \\
\hline Block spam users. & 311 & $34.1 \%$ \\
\hline Control who can message. & 333 & $36.5 \%$ \\
\hline Restrict visibility of my profile. & 364 & $39.9 \%$ \\
\hline Restrict photo tagging. & 139 & $15.2 \%$ \\
\hline Set alarm if login occurs from unknown. & 305 & $33.4 \%$ \\
\hline I don't use any mechanism. & 241 & $26.4 \%$ \\
\hline
\end{tabular}

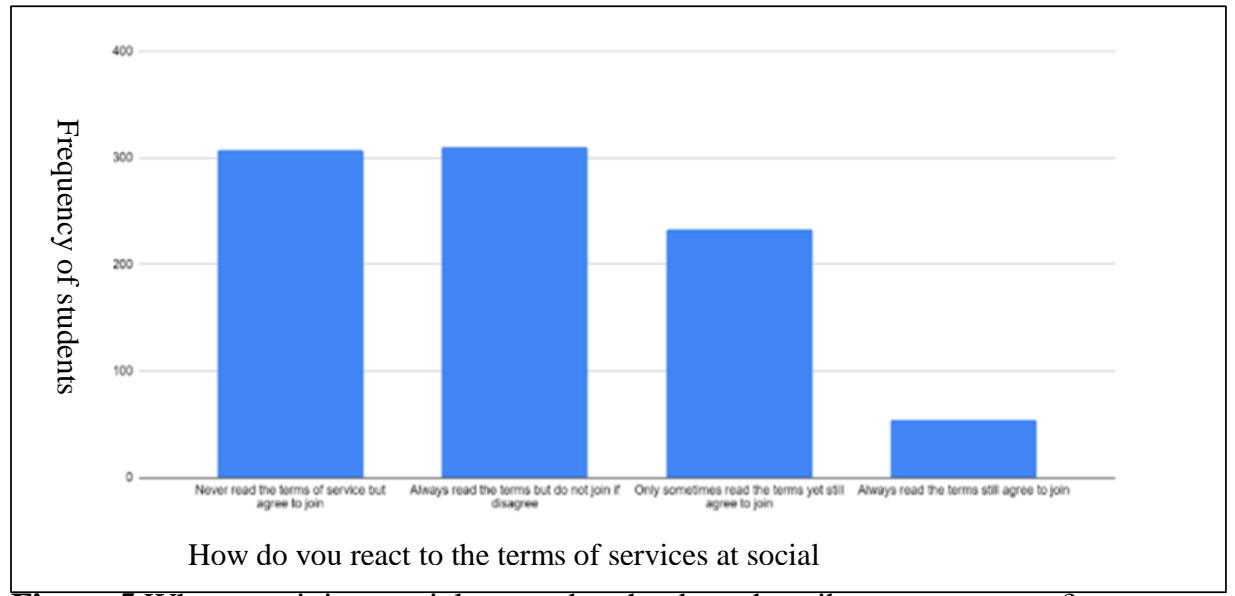

Figure 5 When you join a social network, what best describes you as a user?

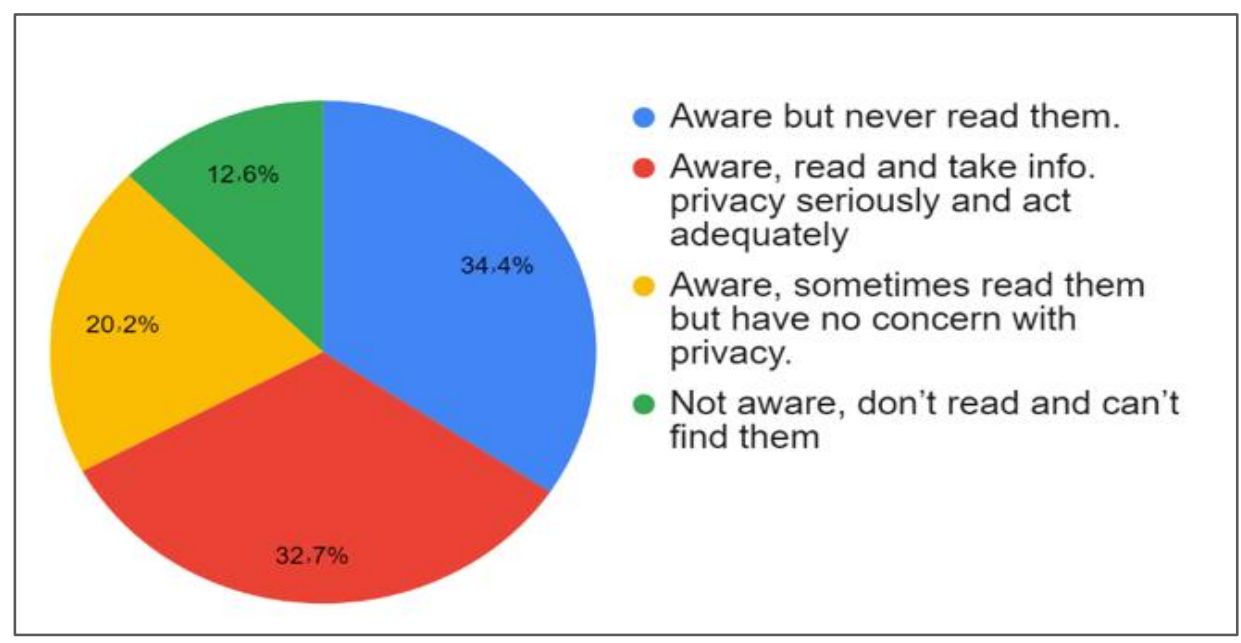

Figure 6 With regard to the privacy policies of social networks, which answer describes you as a user? 


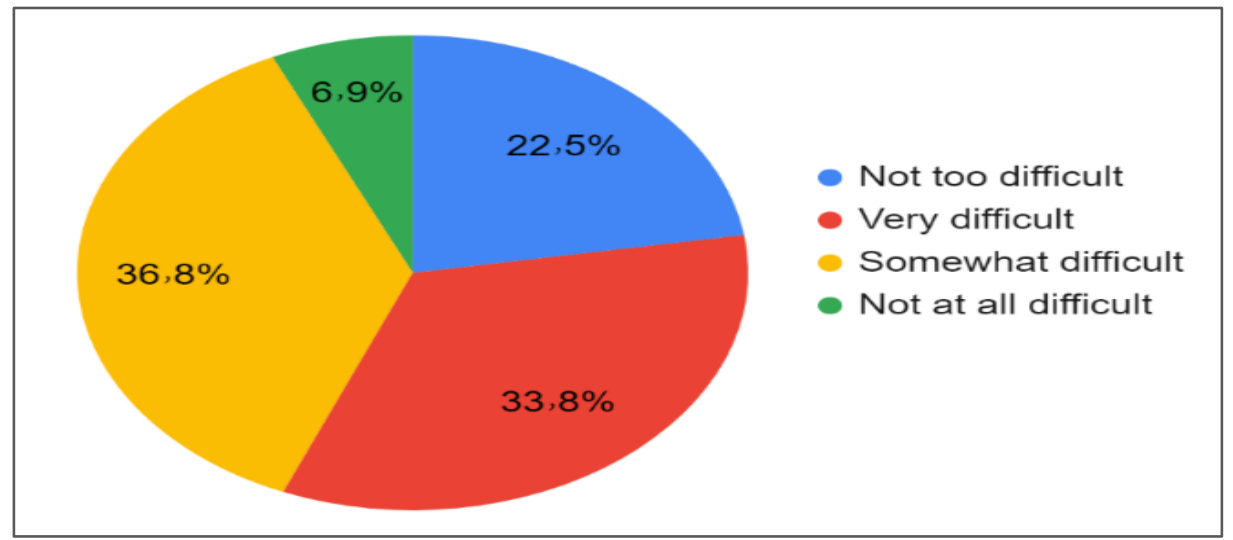

Figure 7 If others try to learn or disclose your user information on social media pages, what is the impact?

\section{Discussion}

Table 1: shows the demographic information of the participant students from Qassim university, and we can see that most of them $(68.3 \%)$ were female, while the education levels were distributed among them as foundation $(7.1 \%)$, undergraduate $(78 \%)$, and postgraduate $(6 \%)$. Also, almost half of the respondents $(49.6 \%)$ study in the science field, $(43.6 \%)$ study in the arts and humanities field and the remainder study medical science.

The general findings of this study suggest that all the Qassim University students from various departments, different colleges and levels use SNS and are using various types of social media. Moreover, the students at Qassim University are using two or more different social media platforms. Table 3 explains that the students use the most common SNS available in Saudi Arabia as follows, decreasing: WhatsApp, Twitter, Snapchat, Instagram, and Facebook. Most of them use WhatsApp, and the least used social media network was Facebook. Whereas, some of them used other types of SNS. Concerning these results, a study conducted in Qassim University in Saudi Arabia also discovered that WhatsApp and Twitter were the most used social networks between students. On the other hand, Facebook was the least used social network between students of Qassim University.

Figure 1 shows the time spent on social media by students, and it can be observed that close to half of them $(43.5 \%)$ used SNS platforms for more than four hours a day, while, only a few (5.5) students spent less than an hour using SNS platforms. Regarding how long students have been part of SNS, most of them $(86.9 \%)$ started to be a member of one the SNS platforms for more than four years, while only (1.3\%) joined the SNS platforms less than one year ago. Smartphones are the most popular devices (99\%) used to access and browse the SNS platforms by the students of Qassim University. While desktop devices were not preferred tools to access SNS platforms. A number of students use different types of devices to access and browse the SNS platforms. Concerning these results, a study found that as most of the students in Qassim university use smartphones to access and browse the SNS, which are easy to use and available near the user most of the time, that led them to spend more time on SNS platforms and join more types of SNS platforms for different purposes.

As can be seen in Table 5, the first goal of using SNS platforms is to connect with friends $(77.5 \%)$, which is expected, since students at university have classmates and other friends from previous levels of education. The second goal for using these SNS platforms is connecting with new friends with similar interests (28.3\%), which reflect that some of the students are looking at other students in other universities who are studying the same subject or have the same hobbies. The third goal of using SNS found between the students (35.9\%) was sharing knowledge and expressing their opinion about a topic. Finally, $(7.8 \%)$ of the students at Qassim university were not sure about their reasons for joining SNS platform(s). On the interaction in social media by the students to share or comment publicly, Figure 3 shows that according to the outlooks of the participants, more than 300 students share their opinion or comment in public, while around the same number of students rarely share their opinion or comment publicly. The remaining students are distributed nearly equally between the three categories frequently, often, and never share their opinion or comment publicly. 
In the section about account privacy settings, Figure 4 shows how the students set privacy used in their current accounts on SNS platforms. It shows clearly that most of the students $(88.1 \%)$ chose their privacy level for their account without consulting anybody; conversely $(1.5 \%)$ of the students use the default privacy settings. Also, (7.1\%) of the students ask members of their families or friends about what they should for privacy control in their current accounts of SNS. Only $(3.3 \%)$ of students obtain a consultation with technical people about setting their SNS account privacy. The SNS platforms offer a number of privacy control mechanisms to meet the requirements of most users, which include, in this study, control how others find me, block spam, control who can message me, restrict my profile visibility, limit photo tagging, set alarm if login happens from unknown source. The study found that nearly half of the students $(44.1 \%)$ control the how others can find me' mechanism, while only (15.2\%) of the students use restrict photo tagging mechanisms. The students use the mechanisms block spam, control who can message, limit visibility of my profile by $(34.1 \%$, $36.6 \%, 39.9 \%$ ), respectively.

With regard to reading the terms of service agreement of SNS platforms, Figure 5 shows that when any new user logs in, either they study the terms and conditions or ignore them. It can be clearly seen that more than 300 students agree that when they login as new users, they ignore the terms and conditions and don't even read them. Only less than 100 people study the full details when they login to social networks. This result reflects on whether the privacy policies of the SNS platforms are looked at, where a third of the students $(34.4 \%)$ don't read terms and conditions while joining social networks, however, they are aware of the privacy factors. While $(32.7 \%)$ of the students realize the importance of all the terms and conditions regarding privacy and read them in their entirety. Only (12.6\%) of the students do not care about the terms and conditions regarding privacy.

The difficulty or ease of hiding user's private information from the user's social network pages is one of the privacy techniques for users of SNS platforms and depend on many parameters such as SNS platform settings and the technology culture of the user. Around a third (33.8\%) of the students find hiding a user's private information is very difficult. Whereas $(36.8 \%)$ of students find it somewhat difficult to maintain their privacy and $(22.5 \%)$ of students conceal their private information easily.

\section{Conclusion}

In this paper, awareness of information privacy is investigated based on the students of Qassim University who use SNS. A detailed study was carried out with 913 student responses from various departments and of differing gender, age, and field of study. The study shows that $89 \%$ of the students use WhatsApp, 74.8\% use Snapchat, 3.9\% use Facebook, $77 \%$ use Twitter, and $62 \%$ use Instagram, while $77.5 \%$ of the students use social media for connecting with friends and avoid connecting with new people for security reasons. Moreover, $44.1 \%$ of users control whether they can be searched for, $34.1 \%$ block spam users, $36.5 \%$ control inbox messaging, $39.9 \%$ restrict profile visibility, and $33.4 \%$ set alarms for logins of their profile. This analysis reveals that the majority of users in every SNS are concerned about their privacy and personal information. All the users ensure that their privacy is maintained, personal information is not shared, and in case of violation of privacy, the government must take action on it.

\section{Acknowledgment}

None.

\section{Conflicts of interest}

The authors have no conflicts of interest to declare.

\section{References}

[1] Aljohani M, Nisbet A, Blincoe K. A survey of social media users privacy settings \& information disclosure. The proceedings of Australian information security management conference, cowan university, Perth, Western Australia. 2016 (pp.67-75).

[2] Li K, Wang X, Li K, Che J. Information privacy disclosure on social network sites. Nankai Business Review International. 2016; 3(7):282-300.

[3] Abril PS, Levin A, Del Riego A. Blurred boundaries: social media privacy and the twenty-first-century employee. American Business Law Journal. 2012; 49(1):63-124.

[4] Del Riego A, Sanchez Abril P, Levin A. Your password or your paycheck? a job applicant's murky right to social media privacy. Journal of Internet Law. 2012; 16(3):17-26.

[5] https://www.managingip.com/article/b1kc1mcwg39np s/to-tweet-or-not-to-tweet-advice-on-social-media. Accessed 22 May 2020.

[6] Van Schaik P, Jansen J, Onibokun J, Camp J, Kusev $P$. Security and privacy in online social networking: risk perceptions and precautionary behaviour. Computers in Human Behavior. 2018; 78:283-97.

[7] https://www.globalmediainsight.com/blog/saudiarabia-social-media-statistics. Accessed 22 May 2020.

[8] AlSagri HS, AlAboodi SS. Privacy awareness of online social networking in Saudi Arabia. In international conference on cyber situational 
awareness, data analytics and assessment 2015 (pp. 16). IEEE.

[9] Aljasir S, Woodcock A, Harrison S. Facebook in Saudi Arabia: some aspects of facebook usage by Saudi university students. International Journal of Engineering and Technology. 2013; 5(1):80-4.

[10] Shin DH. The effects of trust, security and privacy in social networking: a security-based approach to understand the pattern of adoption. Interacting with Computers. 2010; 22(5):428-38.

[11] Al Johani M. Personal information disclosure and privacy in social networking sites (Doctoral dissertation, Auckland University of Technology). 2016.

[12] Strater K, Lipford HR. Strategies and struggles with privacy in an online social networking community. People and Computers XXII Culture, Creativity, Interaction. 2008:111-9.

[13] Bunnig C, Cap CH. Ad hoc privacy management in ubiquitous computing environments. In international conference on advances in human-oriented and personalized mechanisms, technologies, and services 2009 (pp. 85-90). IEEE.

[14] Ni Q, Bertino E, Lobo J, Brodie C, Karat CM, Karat J, et al. Privacy-aware role-based access control. ACM Transactions on Information and System Security. 2010; 13(3):1-31.

[15] Taheri S, Hartung S, Hogrefe D. Achieving receiver location privacy in mobile ad hoc networks. In international conference on social computing 2010 (pp. 800-7). IEEE.

[16] Sanchez-Casado N, Navarro JG, Wensley A, Tomaseti-Solano E. Social networking sites as a learning tool. The Learning Organization. 2016.

[17] Bhandari RS, Bansal S. Privacy concerns with social networking sites: an empirical investigation of users in national capital region (NCR), India. South Asian Journal of Management. 2019; 26(3):68-87.

[18] Hong W, Thong JY. Internet privacy concerns: an integrated conceptualization and four empirical studies. Mis Quarterly. 2013; 37(1):275-98.

[19] Hsu CL, Lin JC. An empirical examination of consumer adoption of internet of things services: network externalities and concern for information privacy perspectives. Computers in Human Behavior. 2016; 62:516-27.

[20] Xie E, Teo HH, Wan W. Volunteering personal information on the internet: effects of reputation, privacy notices, and rewards on online consumer behavior. Marketing Letters. 2006; 17(1):61-74.

[21] Youn S. Determinants of online privacy concern and its influence on privacy protection behaviors among young adolescents. Journal of Consumer Affairs. 2009; 43(3):389-418.

[22] Martin KD, Murphy PE. The role of data privacy in marketing. Journal of the Academy of Marketing Science. 2017; 45(2):135-55.

[23] Dhawan S, Singh K, Goel S. Impact of privacy attitude, concern and awareness on use of online social networking. In international conference-confluence the next generation information technology summit (Confluence) 2014 (pp. 14-7). IEEE.

[24] Krasnova H, Günther O, Spiekermann S, Koroleva K. Privacy concerns and identity in online social networks. Identity in the Information Society. 2009; 2(1):39-63.

[25] Gupta B, Chennamaneni A. Understanding online privacy protection behavior of the older adults: an empirical investigation. Journal of Information Technology Management. 2018; 29(3):1-3.

[26] Prince C. Do consumers want to control their personal data? empirical evidence. International Journal of Human-Computer Studies. 2018; 110:21-32.

[27] Dinev T, Hart P. An extended privacy calculus model for e-commerce transactions. Information Systems Research. 2006; 17(1):61-80.

[28] Rotenberg M. Privacy in the modern age: the search for solutions. New Press. 2015.

[29] Al Hasib A. Threats of online social networks. International Journal of Computer Science and Network Security. 2009; 9(11):288-93.

[30] Hargittai E, Marwick A. "What can I really do?" explaining the privacy paradox with online apathy. International Journal of Communication. 2016.

[31] Talib S, Ismail NA, Olowolayemo A, Naser SA, Haron SZ, Yusof AH. Social networks privacy policy awareness among undergraduate students: the case of Twitter. In the international conference on information and communication technology for the muslim world 2014 (pp. 1-5). IEEE.

[32] Aldhafferi N, Watson C, Sajeev AS. Personal information privacy settings of online social networks and their suitability for mobile internet devices. arXiv preprint arXiv:1305.2770. 2013.

[33] O'Brien D, Torres AM. Social networking and online privacy: facebook users' perceptions. Irish Journal of Management. 2012.

[34] Ibrahim S, Tan Q. A study on information privacy issue on social networks. ISeCure-The ISC International Journal of Information Security. 2019; 11(3):19-27.

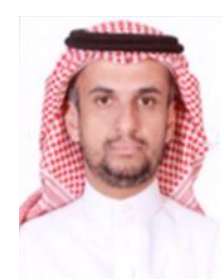

Abdullah Alabdulatif is Assistant Professor of Computer Department, College of Sciences and Arts, Qassim University. He graduated from Qassim University, Saudi Arabia in 2004. He received a bachelor of computer Science degree. Then entered Newcastle University, UK and received a Master of Computer Security and Resilience degree in 2009 and $\mathrm{PhD}$ in Information Security from Nottingham Trent University in 2014. He has 6 research papers in refereed international journals and conferences. $\mathrm{He}$ is interesting research in Academic \& Research includes Wireless security, IoT security, Blockchain Security. Email: A.Alabdulatif@qu.edu.sa 
International Journal of Advanced Computer Research, Vol 10(50)

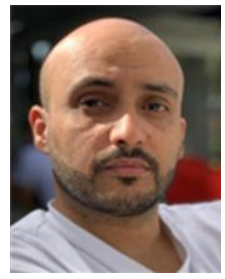

Fahad Alturise is currently working as an Assistant Professor in the Computer Department, College of Science and Arts in Ar Rass, Qassim University, Saudi Arabia. He has an experience of twelve years in the field of teaching and research. He holds a $\mathrm{PhD}$ in Information Technology from Flinders University. His primary research interests include elearning, e-services, e-government, IOT, ICT adaption, IT security and Software Engineering. He has published 12 papers in international journals/conference proceedings $\mathrm{He}$ was a member of the Australian Computer Society (ACS) for 4 years.

Email: falturise@qu.edu.sa 